\title{
The Model of Infrastructural Support of Regional Innovative Development
}

\author{
Natalya Kalenskaya \\ Kazan Federal University, Kremlyovskaya st. 18, Kazan 420111, Russia \\ Email: kalen7979@mail.ru
}

\section{Doi:10.5901/mjss.2014.v5n18p317}

\section{Abstract}

\begin{abstract}
The article considers an invariance of the infrastructural ensuring architecture of innovative development of the region, based on which the optimal model of the infrastructural ensuring is offered on condition of the optimal resource support that allows increasing the effectiveness of the region. General economic development and its aggregated parameters became the precondition for understanding the processes of infrastructural ensuring, its modernization and relation with structural changes of sustainable development of economic systems. This is primarily reflected in the so-called "vectors of infrastructural ensuring», in the process of creating an environment supporting business processes and ensuring of directions for sustainable development and competitiveness. Thus, it should be noted that the infrastructural ensuring is developed within the scope of the evolutionary process, appropriately responding to all transformations and upgrading of economic systems.
\end{abstract}

Keywords: Infrastructure, innovative development, matrix of impact, infrastructural ensuring;

\section{Introduction}

The formation process of infrastructural ensuring of innovative development of the region requires the availability of certain effectiveness parameters and close interrelationship between elements within the economic system. The most typical parameters are those which form a "subspace" of infrastructural elements and which are in close dependence to each other.

The qualitative level infrastructural ensuring is determined by the closeness of the connection between the elements of the innovative and market infrastructure at the same time it is determined by availability of institutional agreements between the elements of the system [5]. The institutional environment provides this interconnection, which can be identified with such category as "infrastructure of achievements" these are universities, scientific organizations, NTC, technology parks, project structures, where agreements take material form and are executed in certain institutional framework [3]. The infrastructure of achievements of the innovation system in the quantitative measurement can be represented by a number of patents and licenses, technical developments, business agreements, know-how, inventor's certificates. It should be noted that the next step of infrastructural achievements is commercializing of intangible assets, which is accompanied by the infrastructural ensuring.

\section{Infrastructural Support}

\subsection{Conditions}

The quality of the level of infrastructural support for the given moment of time ( $\left.\mathrm{t}_{\mathrm{i}}\right)$ is determined by the coefficient $\mathrm{K}_{\mathrm{n}}$. Furthermore, as the resource for all types of formation of infrastructural ensuring elements is allocated for the innovative development of the system, the coefficient $\left(K_{n}\right)$ ti is changed. The change of this coefficient depends on the type of the system and the level of market, innovative infrastructure and institutional infrastructure. Thus, under the influence of changes of the institutional environment, the basic quality of infrastructural ensuring is shown, this is its invariance. In this case, under the invariance we mean the ability of infrastructural support architecture to combine either all of its elements, or some of them, depending on the resource capacity of the system (of the region).

Researches in the field of innovative development of the system shows that the quality level of infrastructural ensuring is proportional to an allocated resource for its formation with the coefficient of proportionality of $C_{p}$, i.e. the ratio of resources allocated to the market infrastructure and innovation infrastructure.

$\left(K_{n}\right) t_{i}=K_{p} C_{p}$. 
As already mentioned the infrastructural ensuring is invariant. The invariance is based on the following reasons:

- A type of system (we consider innovation-oriented system);

- A clustered feature (is there a clustered formation in the region);

- A feature of the institutional arrangements within the clustered formations.

Considering the interaction of infrastructure elements, its architecture should be taken into account under invariant conditions. If we consider the innovation system within an industrial cluster, the interaction of a set of infrastructure elements will be formed under the influence of large industrial-economic complex, revealing relationship of sectored specificity of cluster and the type of infrastructural ensuring.

\subsection{Infrastructural ensuring}

Furthermore, it should be noted that processes associated with a transfer of technology to innovation-oriented enterprises is accompanied by infrastructural support. For example, the analysis of the innovation capacity of enterprises of the Republic of Tatarstan, shows that an increase of industrial enterprises dealing innovative activities is observed since 2005 [2]. In 2005 there were 95, and by 2009 their number has increased to 107, there were 122 organizations dealing with innovative activities in $2009,76 \%$ of innovation - active enterprises is accounted for the proportion of manufacturing industries. However, there is a lack of resources allocated to the development of infrastructural support of commercialization of R\&D in such areas as chemistry petrochemicals, engineering.

Our research showed that the maximum effect of infrastructural ensuring is achieved on condition that the overall limited resource is shared equally between the direct productive activities of the enterprise and ensuring infrastructure of the innovative development of the region. There is a need for an optimal allocation of resources between innovative development via an innovative infrastructure of the region and the development of production via the development of the innovative infrastructure. Thus, the maximum effect from the innovative infrastructure is achieved in case when the resource is shared equally between the development of industrial infrastructure within a system and resources of involved components of the innovative infrastructure.

In its turn, the allocation of the limited resource of the region into equal components allows to reach both the maximum value of the total economic effect to the region, and the maximum value of the level of the infrastructural support.

Particular interest is the mechanism of binary integration, which is supposed:

- A simultaneous operation of infrastructures of innovative development in several innovative systems;

- A combination of innovative infrastructure and market infrastructure, as integral components of infrastructure formation of innovative development of the region.

A typical peculiarity of formation of an innovative type of economic system is its autonomy and there is an optimal allocation of limited resources between the direct industrial process and process of formation of an infrastructure of innovative development within individual system. Under such conditions, there is no common space of an innovative development. A creation of a mechanism realizing an integration of the elements of infrastructure of innovative development, both under conditions of the innovative system and the innovative cluster, will let to increase significantly the total effect. By the optimal consideration a total maximum effect of all innovative systems (with high innovative index) will be equal to the sum of the maximum effects.

There are two structure-forming factors of infrastructural ensuring, these are a factor determining the level of a market infrastructure and a factor determining the level of innovative infrastructure. A consideration of the interaction of these factors is currently possible in the situational space. Let's consider the situational space $R_{\mathrm{ri}}$ and $\mathrm{K}_{\mathrm{ki}}$, where the space $K_{k i}$ characterizes an innovative infrastructure and $R_{\mathrm{ri}}$ characterizes a market infrastructure.

$K_{k i}$ is formed by the set of elements $\left(k_{1}, k_{2}, k_{3}\right)$. In this case, we consider that every element $k i$ reflects the existence of the basic elements of the innovative infrastructure (technology parks, business incubators, innovative centers), where $i$ is a number of present elements (1, 2, 3, etc.).

$\mathrm{R}_{\mathrm{ri}}$ is formed by a set of elements $\left(r_{1}, r_{2}, r_{3}\right)$ where $r j$ reflects the existence of elements of a market infrastructure (investment funds, venture capital funds, consulting firms), where $i$ is a number of elements of market infrastructure.

Below we present a matrix showing the impact of infrastructural elements based on the suggested two-factor model of analysis of the effectiveness of the infrastructural support. 
Table 1. The matrix of elements of the infrastructural support

\begin{tabular}{cccc|} 
& $\mathrm{r}_{1}$ & $\mathrm{r}_{2}$ & $\mathrm{r}_{3}$ \\
$\mathrm{~K}_{1}$ & $\mathrm{~K}_{1} \mathrm{r}_{1}$ & $\mathrm{~K}_{1} \mathrm{r}_{2}$ & $\mathrm{~K}_{1} \mathrm{r}_{3}$ \\
$\mathrm{~K}_{2}$ & $\mathrm{~K}_{2} \mathrm{r}_{1}$ & $\mathrm{~K}_{2} \mathrm{r}_{2}$ & $\mathrm{~K}_{2} \mathrm{r}_{3}$ \\
$\mathrm{~K}_{3}$ & $\mathrm{~K}_{3} \mathrm{r}_{1}$ & $\mathrm{~K}_{3} \mathrm{r}_{2}$ & $\mathrm{~K}_{3} \mathrm{r}_{3}$
\end{tabular}

The matrix reflects all possible interactions or combinations of infrastructural elements, at the same time it allows to take into account a regional specificity and to identify the optimal combination of infrastructural elements, and the specificity of the region, in its turn, is reflected by the «weight» of impact elements of the market infrastructure or the innovative infrastructure.

\subsection{Republic of Tatarstan model}

For example, in the Republic of Tatarstan for 12 technology parks there is one venture fund, one investment fund and one innovative technology center, i.e. the number of elements of innovative infrastructure more than the number of elements of market infrastructure, but in practice, the quantity doesn't guarantee the quality and speed of technology transfer to industrial complex because there is no an interaction with the market elements [1].

Considering the weight of the importance of factors $\mathrm{R}_{\mathrm{ri}} \mathrm{x} \mathrm{K}_{\mathrm{ki}}$ with the help of experts (or statistically), we will get the invariant model of infrastructural support (table 1). The effectiveness of infrastructural ensuring depends on the components of the market infrastructure and an innovative infrastructure, it is determined by an existence of the separate elements but not by their interchangeability. The suggested model of infrastructural support of innovative development of the region (see a table 1) is based on the idea of infrastructural elements in the form of Boolean variables (1 is available, 0 is not available). 5 points is given for every available element, a sequence of variants (technology parks, business incubators, innovative centers, investment fund, venture capital fund, a consulting firm).

Table 2. Invariant model of infrastructural support

\begin{tabular}{|c|c|c|c|c|}
\hline \multicolumn{5}{|c|}{ № Variants of combination of elements Innovative infrastructure Market infrastructure The effectiveness of infrastructural support } \\
\hline 1 & 000100 & 0 & 5 & 5 \\
\hline 2 & 001000 & 5 & 0 & 5 \\
\hline 3 & 001100 & 5 & 5 & 10 \\
\hline 4 & 011001 & 10 & 5 & 15 \\
\hline 5 & 001110 & 5 & 10 & 15 \\
\hline 6 & 011100 & 10 & 5 & 15 \\
\hline 7 & 111101 & 15 & 10 & 25 \\
\hline 8 & 111100 & 15 & 5 & 20 \\
\hline 9 & 111011 & 15 & 10 & 25 \\
\hline 10 & 111110 & 15 & 10 & 25 \\
\hline 11 & 111001 & 15 & 5 & 20 \\
\hline 12 & 111111 & 15 & 15 & 30 \\
\hline
\end{tabular}

Organizational and structural problem of optimization can be solved with the introduction of restrictions on the field of factors $R_{\mathrm{ri}} \times K_{\mathrm{ki}}$, i.e. when to use a particular type of innovative infrastructure. This approach lets to take into account industrial specificity of the region, which requires that the infrastructural elements have been presented in every industry, and when the support extends to the whole industrial complex of the region.

A consideration of the invariant model was realized on the cognitive level that implies an event-situational analysis and, at the same time, the area of allowed values is discrete.

For many innovation-oriented systems the global maximum (when all elements of the infrastructural ensuring are maximum - developed and take place) is not reachable because there are a number of restrictions preventing to get to the area of maximal solutions [4]. One of them is the low return of innovation - active enterprises of the region, though they are the basis of intensive economic growth via innovative development. Therefore, a search of the individual local possible maximum of the region must be realized for every system.

With the introduction of the distribution of the weights out of the Boolean variables, we move on to the scenarios of combination of infrastructural ensuring parameters, and here there is an opportunity of constructing a matrix of threshold 
values of infrastructural support of innovative development.

With the introduction of allocation of weights out of the Boolean variables, we pass to scenarios of a combination of infrastructural support parameters, and there is an opportunity of constructing a matrix of threshold values of infrastructural ensuring of innovative development [4].

An infrastructural support as it was noted earlier, is organizational mechanism and its own effect should be evaluated by any its elements. If there is no such effect, then one of the tasks of infrastructural ensuring is broken, it's a strengthening of a synergistic effect. In the analysis of the economic effectiveness of infrastructural support it is necessary to instantiate three conditions:

- The choice of comparative options;

- The definition of a subject where a result is shown (a region, a cluster, a complex, an industry);

- The comparability of options.

A choice of conditions of an effectiveness evaluation is based on the scale of its activities and the expenditure source of the forming of institutional arrangements within the framework of integration processes of the region, where the effectiveness of infrastructural ensuring is determined by:

- Minimizing timeline for achieving economic results;

- Increasing of the share of high-tech enterprises in the sphere of small-scale business;

- Strengthening of the scientific and technical potential;

- Using the economic result by scientific and technical potential;

- Increasing of a share of shipped innovative product;

- Increasing of the share of innovative product in the GRP.

\section{Conclusions}

The complexity of processes of the effectiveness evaluation of infrastructural ensuring and the innovative activity consists of subjectivity and relativity of indicators of the effectiveness. On today an absence of such indicators is replaced by the use of standards. That's why the transition to network structures and standards is considered in Russian practice as a basis of innovative development. The following complex problems can be solved by evaluation standards of an innovation:

- An expansion of the scale and simplification the entry of Russian companies to world markets;

- A formation of a system of standards of innovative development;

- Increasing the competitiveness of producers.

A qualitative indicator of infrastructural ensuring is a use of the science results for solving applied industrial and sectored problems. This indicator can be represented by the following formula:

IS $\left(I^{*} \mathrm{~S}^{*} \mathrm{H}^{*} \mathrm{R}\right) \mathrm{ER}$

where,

IS is an infrastructural ensuring

$I$ is an involved innovative potential

$S$ is an involved science potential

$H$ is an involved human potential

$R$ is an involved resource potential

$E R$ is an achieved economic result Involved innovative potential / can be represented by of indicators:

- the number of scientific discoveries and inventions;

- the number of new materials and supplies;

- the number of new products and constructions;

- the number of new technological processes;

- the number of innovative proposals.

Involved science potential $S$ can be represented by of indicators:

- the number of academic institutions;

- the number of industrial research institutes;

- the number of problem institutions of the Academy of Sciences of the Republic of Tatarstan;

- the number of scientific schools of leading universities. 
Involved human potential $H$ can be represented by of indicators:

- the number of students in the natural sciences;

- the number of scientists and researchers (according to sectors);

- the number of intellectual property objects (grants, patents, certificates);

- the number of Ph.D. experts employed in the industry.

Involved resource potential $R$ can be represented by of indicators:

- allocated funds from the federal budget;

- allocated funds from the regional budget;

- funds of enterprises;

- foreign investment.

The value of achieved economic result $(E R)$ will be proportionally changed from increase / decrease the influence of the elements of infrastructural support. It should be noted that an economic result means:

- an increasing the competitiveness of products;

- an innovative renewal of fixed capital;

- an acceleration of economic growth;

- an improvement of the level and quality of life;

- improving the use of natural resources and protection of the environment;

- an increasing of the proportion of innovative products in the GRP.

Depending on the conditions of indicators within the involved potential one or another element will compensate for its weight in the total system. Thus, it is possible to vary involving of the infrastructural ensuring elements in order to get the economic result. The value of ER of solutions of applied industrial-sectored problems by sustainable development directly depends on the functions of infrastructural elements.

Table 3. The phase area of the values of infrastructural support

\begin{tabular}{|c|c|c|c|c|}
\hline \multirow{2}{*}{ Indicator name } & \multicolumn{4}{|c|}{ The threshold values of the phases } \\
\hline & Risk phase & Critical phase & Optimal state phase & Advantage phase \\
\hline \multicolumn{5}{|c|}{ Infrastructural ensuring IE } \\
\hline I-involved innovative potential & & & + & \\
\hline S - involved science potential & & & + & \\
\hline $\mathrm{H}$ - involved human potential & & + & & \\
\hline $\mathrm{R}$ - involved resource potential & & + & & \\
\hline
\end{tabular}

The table shows four main variants of qualitative impact of infrastructure. To achieve the status of sustainable development of the system (phase of the optimal state and the advantage phase) threshold values of infrastructural indicators should not go beyond the phase of the optimal state. In the sectored aspect, it should be noted that the influence of the infrastructural ensuring elements will be strengthened by involving an industrial enterprise to a particular cluster. Under conditions e.g., of the Republic of Tatarstan an innovative and a scientific potential is involved, which is reflected in the result, i.e., involving into an «optimal state phase» while, as a resource potential and human potential are in a «critical phase». As a result, the policy of innovative development of the region is constructed taking into account the limits and opportunities of scientific and innovative areas, that's why models and elements of the infrastructure of the regions are different and can not be «stereotyped», although they are similar in its functions, which is based on the invariant principles.

Thus, the proposed invariant model allows modeling the architecture of infrastructural ensuring, when use of all elements is optimal, and when its presence is partial. The proposed model depends on the threshold values of infrastructural support, which allow modeling the optimal scenario of infrastructural ensuring of the innovative development and as a consequence it leads to the effectiveness of the region in general.

\section{References}

Mettam, G. R., \& Adams, L. B. (1994). How to prepare an electronic version of your article. In B. S. Jones, \& R. Z. Smith (Eds.), Introduction to the electronic age (pp. 281-304).New York: E-Publishing Inc.

Strunk, W., Jr., \& White, E. B. (1979). The elements of style. (3rd ed.).New York: Macmillan, (Chapter 4).

Van der Geer, J., Hanraads, J. A. J., \& Lupton R. A. (2000). The art of writing a scientific article. Journal of Scientific Communications, 
$163,51-59$

Nailya Bagautdinova, Ilshat Gafurov, Nataliya Kalenskaya and Aida Novenkova (2012). The Regional Development Strategy Based on Territorial Marketing (The Case of Russia). World Applied Sciences Journal 18 (Special Issue of Economics): 179-184.

Bagautdinova, N.G., Murtazina, G.R., Fazlieva, E.P., Naida, A.M. (2013). Improvement of the regional management system using the labor potential index. World Applied Sciences Journal, 27(1), 107-111.

Bagautdinova, N.G., Galeeva, G.T., Kundakchyan, R.M.(2013). Development of the corporate management system in the modern context. World Applied Sciences Journal, 27(13), 43-47.

Sarkin, A.V., Bagautdinova, N.G., Averianov, B.A. Development and implementation of adaptive science-intensive manufacture management system based on management processes automation // World Applied Sciences Journal, 27(13), 2013, 159-164.

Sarkin, A.V., Bagautdinova, N.G., Averianov, B.A. Development of science-intensive strategy in machinery-building company in contemporary Russia// World Applied Sciences Journal, 27(13), 2013, 24-28.

Melnik A.N. Methodological Foundations of the Formation of the Energy Strategy of an Enterprise / A.N. Melnik, L.V. Lukishina, R.R. Khabibrakhmanov // World Applied Sciences Journal. - 2013. - v. 23 (8). - pp. 1085-1089.

Melnik A.N. The Organization of Russian Power Market in Modern Conditions / A.N. Melnik, O.N. Mustafina // Middle-East Journal of Scientific Research. - 2013. - v. 13 - pp. 91-94.

Kirshin I.A., Datsyk A.A., Titov A.V. Forecasting the Dynamics of an Innovative Cycle. - World Applied Sciences Journal (Economics, Management and Finance). - 2013. - №27. - P. 197 - 201.

Glebova I.S., Sadyrtdinov R. and Rodnyansky D. Impact Analysis of Investment Attractiveness of the Republic of Tatarstan on Fixed Investments of its Leading Companies // World Applied Sciences Journal 26 (7): 911-916, 2013.

Glebova I.S., Khabibrakhmanova R. and Yasnitskaya Y. The Analysis of the Impact of the Investment Attractiveness Factors of the Region on the Fixed Capital Investments in the Economy of the Republic of Tatarstan II Middle-East Journal of Scientific Research 17 (10): 1498-1502, 2013.

Panasyuk, M.V., Bagautdinova, N.G., Safiullin, L.N., Novenkova, A.Z. Territorial approach to solving the region strategic management problems // World Applied Sciences Journal, 27(13), 2013, 149-153. 